\title{
POLÍTICA EXTERNA BRASILEIRA PARA O SAARA OCIDENTAL \\ Pragmatismo e ruptura
}

\section{Adriano Alberto Smolarek ${ }_{(1)}$ (D)}

E-mail: smolarek01@gmail.com

\section{João Irineu de Resende Miranda}

E-mail: joaoirineu78@gmail.com

(1) Universidade Estadual de Ponta Grossa (UEPG), Ponta Grossa (PR), Brasil.

DOI: $10.1590 / 3610705 / 2021$

\section{Introdução}

O posicionamento de um Estado no cenário internacional é construído em décadas de atuação diplomática e possui reflexos de longo alcance em sua economia e em sua importância política perante o mundo. Atualmente, a política externa brasileira tem se caracterizado por um grande número de açóes e atitudes contrárias à práxis tradicional adotada pelo Itamaraty e referendada pela Constituição Federal Brasileira (Cardoso et. al., 2020). O presente artigo analisa a postura do Estado brasileiro em relação ao conflito entre o Marrocos e o Saara Ocidental. Em seu cerne está o direito à autodeterminação do Saara Ocidental, negado pela invasão e ocupação de grande parte do território do país pelo Marrocos. $\mathrm{O}$ respeito à autodeterminação dos povos é um dos

Artigo recebido em: 07/07/2020

Aprovado em: 04/12/2020 princípios constitucionais que regem o Brasil em suas relaçóes internacionais, conforme o artigo 4, III da Constituição Federal. A diplomacia brasileira historicamente respeitou esse princípio e nunca aceitou, de forma declarada, a invasão ou a ocupação militar do Marrocos no Saara Ocidental. Conforme se verá no artigo, tal invasão constitui uma catástrofe humanitária, seguida por diversas e graves violaçóes dos direitos humanos cometidas pelo Estado invasor, e agravada pela vergonhosa omissão de naçóes europeias sobre o fato.

Recentemente, a diplomacia e o Estado brasileiro vêm apresentando sinais ambíguos sobre o respeito do país ao princípio da autodeterminação dos povos. Em comunicado conjunto com o chanceler marroquino, o ex-ministro das Relaçóes Exteriores brasileiro Ernesto Araújo, falou em "abandonar a retórica" em relação a questão do Saara Ocidental. Entrementes, pela primeira vez na história, o país recebeu cargueiros com minérios retirados ilegalmente pelo Marrocos do 
território invadido do Saara Ocidental, contrapondo-se à tendência internacional de não aceitação, nos portos e aduanas, de recursos naturais espoliados do país invadido. Teria o atual governo brasileiro descumprido a Constituição e abandonado uma tradição secular da diplomacia do país? O "abandonar a retórica” da nota diplomática brasileira significa associar o país ao cometimento de um ato ilícito internacional? Estas são as questóes que permeiam este artigo.

Utilizando-se de método dedutivo e da documentação indireta como técnica de pesquisa, o trabalho inicia relatando a situação do Saara Ocidental e a configuração da atuação do Marrocos como um ato ilícito internacional. Sobre o Brasil, realizou-se pesquisa histórica e documental dos posicionamentos do país a respeito do princípio da autodeterminação desde seu reconhecimento pela ONU. Por fim, constatou-se mudança de posicionamento por parte do ex-ministro das Relações Exteriores, relacionando-a às operaçóes econômicas do Marrocos no Brasil, analisadas sob o contexto atual.

\section{O conflito no Saara Ocidental}

O território correspondente ao Saara Ocidental é historicamente habitado por tribos berberes que ocupam a região desde o período neolítico (Kormikiari, 2001, p. 15). No entanto, o direito destas tribos ao próprio território foi ignorado na Conferência de Berlim de 1885, que partilhou o continente africano entre alguns países europeus, estabelecendo ali uma relação de domínio territorial alheia à sua composição étnica e sua organização social (Nuzzo, 2012).

Assim, a região do Saara Ocidental foi reconhecida como domínio espanhol, tendo em vista acordos celebrados entre o país e os povos que habitavam a costa da Baía do Río de Oro (McKenna, 2010, p. 167). Os limites da área de influência da Espanha, contudo, só foram consolidados em 1912, com um tratado com a França, então a potência colonial dominante no norte da África (Miguel, 1995, p. 51). Sob domínio espanhol, iniciou-se a fixação da população nômade saaraui, notadamente após a descoberta de uma imensa reserva de fosfato na região de Bucraa, e do desenvolvimento econômico e comercial da cidade de El Aaiún (Suzin \& Daudén, 2011).
Após a Segunda Guerra Mundial, os impérios coloniais europeus entram em crise diante da emergência de uma nova ordem mundial, que substituiria trezentos anos de preponderância política do continente pela bipolaridade entre Estados Unidos e União Soviética. Aproveitando-se da debilidade econômica e militar dos colonizadores, as colônias do Norte da África insurgem-se, buscando independência. A Líbia tornase independente em 1951 e a Tunísia, em 1956. No Marrocos, ainda sob domínio francês, nos anos 1940, havia sido criado o Partido Nacionalista Marroquino (ISTIQLAL) pelo escritor Muhammad Allal al-Fassi (1910-1974). Além de independência, Al-Fassi defendia a criação de um "Grande Marrocos" que submetesse a seu domínio todos os povos de origem berbere. Sua ideologia influenciou o movimento que declarou a independência do Marrocos em 1956 e levou à coroação do rei Hassan II, em 1961, e à constituição do Reino, em 1962 (Miguel, 1995, pp. 85, 89 e 122). A independência do Marrocos instrumentalizada pelo ISTIQLAL teve influência do governo dos Estados Unidos, que temia a proximidade política dos movimentos nacionalistas e anticolonialistas com a União Soviética (Thomas, 2002). Ressalta-se que o Reino do Marrocos possui um relacionamento estreito com os Estados Unidos desde a firma do Tratado de Amizade, em 1787 (Zunes, 1998).

Em vista da insurgência das colônias contra seus dominadores, em 1960 a 15a Assembleia Geral da ONU aprovou a Resolução 1514, ou "Declaração sobre a Garantia de Independência dos Países e Povos Coloniais" (Organização das Naçóes Unidas, 1960). A Declaração consagrou o direito de autodeterminação dos povos, considerando qualquer dominação estrangeira uma forma de negação de direitos humanos fundamentais. Em 1963, a Assembleia Geral da ONU declarou o Saara Ocidental território sob tutela, em vias de descolonização (Wrange, 2019, p. 5).

Neste período a Espanha encontrava-se sob um regime ditatorial fascista avesso ao processo de descolonização (Penna Filho, 2010). Tal postura fez com que o país fosse objeto da Resolução 2229 (XXI) da Assembleia Geral, que determinou a realização de referendo sobre a independência do Saara Ocidental (Organização das Naçóes Unidas, 1966), levando à união da população local que resultou, em 1973, 
na fundação Frente Popular para a Libertação de Saguia-el-Hamra e Río de Oro (parte setentrional e meridional do atual Saara Ocidental), conhecida como Frente Polisario (Santayana, 1987, p. 18).

Em 1974, em meio à instabilidade política do final do período ditatorial, a Espanha realiza um recenseamento populacional para o referendo de independência do Saara Ocidental (Suzin e Daudén, 2011, p. 61). Antes disso, contudo, o Marrocos instou a Corte Internacional de Justiça, durante a Assembleia Geral de 1974, através da Resolução 3292 (XXIX), a produzir um parecer consultivo sobre ser ou não o Saara Ocidental terra nullius quando do início da colonização espanhola. Se a resposta fosse negativa, os juízes e conselheiros jurídicos deveriam definir os vínculos jurídicos entre o território do Saara Ocidental e o Reino do Marrocos e a Mauritânia (Organização das Nações Unidas, 1974). Enquanto isso, aproveitando-se da crise institucional na Espanha, o Marrocos passa a fazer incursões militares ao território do Saara Ocidental, ao mesmo tempo em que pressiona diplomaticamente $\mathrm{o}$ antigo colonizador para assumir o governo da possessão (Miguel, 1995, p. 103, pp. 141-142). Após realizar uma missão ao Saara Ocidental, entretanto, a ONU constata o anseio da população local pela independência e a legitimidade da Frente Polisario como representante do povo saaraui (Suzin e Daudén, 2011, p. 61).

$\mathrm{Na}$ análise do mérito do parecer requerido pelo Marrocos à Assembleia Geral da ONU, a Corte observou que a Espanha iniciou seu processo de colonizaçáo do Saara Ocidental por meio de acordos com chefes tribais locais que, embora nômades, encontravam-se organizados social e politicamente. Por isso, não se podia afirmar que a regiāo fosse terra nullius, conforme descrito pelo Marrocos (Corte Internacional de Justiça, 1975, pontos 80 e 83). Tampouco as teses alternativas foram reconhecidas pelo parecer consultivo. A contiguidade territorial entre estes países e as tribos saarauis foi entendida como algo discutível. Apenas uma minoria tribal na região fronteiriça entre os territórios possuía vínculos com o soberano marroquino, não sendo reconhecida nenhuma prova de soberania ou de administração prévia efetiva do país no território do Saara Ocidental (Corte Internacional de Justiça,
1975, pontos 87 a 89, 92 e 128). Por fim, o parecer da Corte não reconheceu quaisquer pretensóes de soberania no Saara Ocidental e reiterou o direito à autodeterminaçáo do povo saaraui (Corte Internacional de Justiça, 1975, pontos 148 e 161).

Em 16 de outubro de 1975, dia em que o parecer consultivo da Corte Internacional de Justiça foi publicado, o rei Hassan II do Marrocos convocou uma marcha civil para invadir o território do Saara Ocidental (ARSO, s/d). A chamada "Marcha Verde" reuniu em torno de 350 mil pessoas, entre civis e militares, para invadir o território do Saara Ocidental (Suzin e Daudén, 2011, p. 61). Embora o Conselho de Segurança da ONU tenha determinado a retirada imediata do Marrocos do território invadido, através da Resolução n. 380, de 6 de novembro de 1975 (Organização das Naçóes Unidas, 1975), o Marrocos manteve a ocupaçáo militar de dois terços do território do Saara Ocidental como forma de pressionar por negociaçōes com a Espanha. Em novembro de 1975, o país chamou representantes diplomáticos marroquinos a Madri para discutir a situação (Sántha et. al., 2010).

A Frente Polisario iniciou uma resistência armada contra a invasão marroquina, lutando por independência contra a potência colonizadora e contra o invasor. A Espanha, contudo, celebrou secretamente, em 14 de novembro de 1975, um tratado que ficou conhecido como Acordo de Madri (Suzin e Daudén, 2011, p 61). Nele, o país anuncia sua retirada do Saara Ocidental, transferindo a administração do território para o Marrocos e a Mauritânia (Miyares, 2013). Em troca, passa a receber $35 \%$ dos lucros líquidos obtidos com a exploração local de fosfato e direito de pescar livremente no mar territorial do Saara Ocidental (Sántha et. al., 2010). O Acordo de Madri contou também com a atuação da diplomacia dos Estados Unidos, que pressionou a Espanha para favorecer as pretensōes marroquinas, condicionando ao atendimento dessas reivindicaçóes a renovação do acordo militar entre Espanha e os EUA nos termos solicitados pelo governo espanhol (Zunes, 1998).

Em 28 de fevereiro de 1976, dia da retirada espanhola do Saara Ocidental nos termos do Acordo de Madri, a Frente Polisario proclama a independência da República Árabe Saaraui Democrática (RASD). A nova república já nasce em guerra com o Marrocos 
e a Mauritânia, buscando repelir a invasão em seu território (Miguel, 1995, p. 277). Milhares de pessoas abandonam suas casas e fogem para o deserto; bombardeios da força aérea marroquina os obrigam a atravessar a fronteira com a Argélia (Sántha et. al., 2010, p. 179). Tais fatos são condenados pelo Conselho de Segurança da ONU que, contudo, não toma medidas efetivas a respeito, devido à ação dos Estados Unidos e da França (Mundy, 2006). Para Stephen Zunes (1998), a identificação da Frente Polisario à esquerda política foi determinante neste aspecto, e teria levado o Secretário de Estado norte-americano Henry Kissinger a declarar que não queria outra Angola no flanco leste do oceano Atlântico.

Mesmo combatendo Marrocos e Mauritânia, em 1979 a Frente Polisario obtém vitórias que forçam a retirada da Mauritânia do conflito (Santayana, 1987, p.70). Ante a impossibilidade de obter uma vitória definitiva sobre as tropas da Frente Polisario, o Marrocos constrói um muro de 2200 quilômetros de extensão dividindo o território do Saara Ocidental, mantendo as minas de fosfato e as cidades do litoral sob seu controle e isolando a populaçáo saaraui no deserto. Utilizando-se de expertise francesa e norte-americana, o muro é flanqueado por campos minados, tem cercas de arame farpado e casamatas de concreto e aço a cada cinco quilômetros, guarnecido por um efetivo de 150 mil soldados (Sántha et. al., 2010, p. 175).

Em 1984 a República Árabe Saaraui Democrática ingressa na então Organização para Unidade Africana (OUA), mesmo após tentativas de obstrução por parte do Marrocos. O fato propicia uma mediaçáo internacional do conflito, que resulta em solicitação à ONU para intervir no território (Miyares, 2013). Após vários anos de esforços em prol de uma soluçáo diplomática ao conflito, a Resolução 658/1990 do Conselho de Segurança da ONU instituiu a Missão das Naçôes Unidas para o Referendo do Saara Ocidental (MINURSO), com o objetivo de estabelecer um plano de paz que incluísse o cessar-fogo e um referendo para consultar o povo do Saara Ocidental sobre sua independência (Organização das Naçóes Unidas, 1990). A MINURSO obteve o cessar-fogo entre as partes, mas não conseguiu efetivar um plano de paz que promovesse a autonomia da regiáo e o referendo sobre independência, cuja realização é obstada desde 1991 (Organização das Nações Unidas, 1991).

Assim, nas últimas décadas, a atuação da ONU serviu para garantir ao Marrocos a continuidade de sua política de ocupação militar, colonização e, sobretudo, exploração econômica do território do Saara Ocidental, perpetuando uma crise humanitária de grandes proporçóes, como será demonstrado no decorrer do artigo.

\section{O estancamento e a manutençáo do Marrocos no Saara Ocidental ocupado}

Embora o Marrocos exerça poder de fato na maior parte do território do Saara Ocidental, sua situação jurídica em relação ao território ocupado é precária. $\mathrm{O}$ documento que teria transferido o mandato internacional ao país foi considerado inválido pela ONU. Assim, nos acordos internacionais que celebra, sua representatividade em relação aos saaraui é contestada, e sua presença na área ocupada só é tolerada como mal necessário ao processo de paz que a MINURSO visa implementar há décadas.

O Acordo de Madri foi declarado ilegal pela ONU no parecer do Subsecretário para Assuntos Jurídicos Hans Corell, encomendado pelo Conselho de Segurança, este declara textualmente que:

[...] o Acordo de Madrid não transferiu soberania sobre o território, nem conferiu a nenhum dos signatários o status de poder administrador, um status que nem mesmo a Espanha poderia ter transferido unilateralmente. A transferência da autoridade administrativa sobre o território para o Marrocos e a Mauritânia em 1975 não afetou o status internacional do Saara Ocidental como Território Não Autônomo. (Organização das Naçōes Unidas, 2002a) ${ }^{1}$

Assim, desde 1976, o Saara Ocidental permanece na lista dos territórios sob tutela da ONU. Como é a agência que qualifica estes territórios, nos termos da Carta da ONU, a Espanha não possuía titularidade para transferir um território sob sua tutela, sem mencionar a ilegalidade da assinatura sob coação, na constância 
do cerco marroquino às tropas espanholas no Saara Ocidental (Wrange, 2019, p. 8). O acordo também viola o artigo $73 \mathrm{da}$ Carta da ONU, ao depreender que a Espanha é responsável pelo bem-estar e o desenvolvimento do povo do Saara Ocidental. Hans Haugen (2007, pp. 71-76) observa que, na Carta da ONU, o direito à autodeterminação encontra-se no mesmo patamar que os paradigmas dos direitos humanos e da segurança coletiva. Neste sentido, Tatyana Friedrich (2004, p. 35) constata que o artigo 53 da Convenção de Viena, sobre direito dos tratados, estabelece a nulidade daqueles que venham a contrariar jus cogens, e classifica o direito à autodeterminação dos povos nesta categoria. Por fim, Hildebrando Accioly et. al. (2009, p. 234) classificam a presença do Marrocos no Saara Ocidental como "um ilícito internacional".

Nas últimas quatro décadas, quatro ciclos de negociações entre as partes falharam. A partir de 2011, criou-se um impasse, com a recusa do Marrocos a aceitar o referendo sobre a independência do Saara Ocidental (Human Rights Watch, 2019). Na última década, a MINURSO tem se limitado a monitorar o cessar-fogo entre as partes, desarmar campos minados no território e exortar as partes à retomada das negociações em prol da independência (Organização das Naçôes Unidas, 2020).

Tal situação vem causando repetidas derrotas diplomáticas e judiciais ao Marrocos. Muito embora o lobby marroquino e seus esforços para cultivar a imagem do país no exterior sejam uma realidade (Kalpakian, 2006), em 2004 os Estados Unidos denunciaram seu Acordo de Livre Comércio com o país, por entender como ilícitas suas atividades econômicas e comerciais na área ocupada. Da mesma forma, a Uniāo Europeia anulou seu Acordo de Livre Comércio com o Marrocos, enquanto a Alta Corte do Reino Unido excluiu de seu Acordo de Pesca com o país produtos pescados no litoral do Saara Ocidental (Wrange, 2019, pp. 4, 9 e 25).

Analisando os fundamentos jurídicos dessas decisões, Wrange (2019, pp. 2, 3 e 26) afirma que o direito à autodeterminação tem sido a tônica dos argumentos jurisprudenciais; em sua opinião, contudo, já que o Marrocos não possui mandato da ONU sob a regiáo, seria mais correto analisar suas obrigaçóes como ocupante ilegal do território, e não como poder administrativo local. Juridicamente, a ocupação militar de um Estado sob tutela configura uma forma anômala de exercício de autoridade estatal.

Embate similar se verifica no plano do continente africano, tendo em vista que a República Árabe Saaraui Democrática foi aceita em 1984 no quadro de estados-membros da então Organização para a Unidade Africana, ensejando a retirada unilateral do Reino do Marrocos do bloco. Somente em 2017 o Reino retornou à já então União Africana, que manteve o reconhecimento da RASD, opondo países austrais do continente - como Namíbia, África do Sul, Zimbábue - e do norte, como a Argélia (pró RASD), ao Marrocos. Por sua vez, o Marrocos tem empreendido esforços, via articulação políticodiplomática, por manifestações anulatórias do reconhecimento internacional alcançado pela RASD ao longo do tempo (Ribeiro, 2017).

\section{Violaçóes aos direitos humanos cometidos pelo Marrocos no Saara Ocidental ocupado}

Além do vício de origem em sua presença no Saara Ocidental, o papel do Marrocos também é contestado pela comunidade internacional devido a graves e contínuas violaçóes aos direitos humanos. A invasão implicou o deslocamento forçado de milhares de saarauis, que deixaram de suas casas e formam um dos mais antigos contingentes refugiados da África. Além disso, aqueles que permaneceram no território ocupado sofrem com a discriminação social e a marginalização econômica imposta pelo poder ocupante, mantido à custa do regime repressivo.

As violaçóes começaram logo no início da invasão, quando a força aérea marroquina bombardeou a populaçáo civil saaraui em fuga com artefatos contendo napalm e fósforo branco. $\mathrm{Na}$ segunda metade dos anos 1970 , as atividades militares incluíam, ainda, o massacre de comunidades inteiras, o bloqueio do acesso aos refugiados a víveres e o envenenamento de poços no deserto, resultando em uma política de extermínio do povo saaraui (Miguel, 1995, pp. 249-250).

Assim, a população saaraui encontra-se cindida entre aqueles que estão há décadas em campos de refugiados e os que permaneceram no território 
ocupado pelos marroquinos, especialmente nas cidades litorâneas. Estima-se que 200 mil pessoas vivam há mais de quarenta anos em um complexo de cinco campos de refugiados localizados perto da cidade de Tindouf, na Argélia, em uma das regióes mais áridas do deserto do Saara (Santayana, 1987).

Historicamente, a população que permaneceu no território ocupado tem sido alvo de contínuas violaçóes de direitos humanos: tortura, prisóes arbitrárias, perseguição política com restrição de mobilidade, associação e expressão, e desaparecimentos (Sántha et. al., 2010, pp. 183-186). Tais violaçóes se intensificaram após os protestos do campo de Gdeim Izik, em 2010, pouco depois do malogro do quarto ciclo de negociaçóes conduzido pela ONU (Paone, 2010).

Segundo relatórios produzidos pela Human Rights Watch, a tortura é utilizada contra saarauis pelo Marrocos sobretudo no curso de julgamentos militares, após os protestos de Gdeim Izik, como forma de obter confissóes. Segundo relatos das vítimas, tais atos incluíam espancamentos, suspensão das vítimas pelos pés ou punhos, estupro e outras formas de violação sexual (Human Rights Watch, 2017). Além da tortura, foram denunciadas prisóes arbitrárias, repressão violenta de manifestaçóes pelas forças de segurança e desaparecimentos de ativistas pró-independência (Anistia Internacional, 2019).

Analisando o quadro de violaçóes aos direitos humanos cometidas pelo Marrocos contra saarauis, verifica-se que todos os elementos constitutivos estão presentes no Estatuto do Tribunal Penal Internacional para a configuração da prática de crimes contra a humanidade. Contudo, as denúncias à Corte não prosperam por pressão contrária da França, que possui poder de veto no Conselho de Segurança, e pelo fato da ONU não reconhecer o Saara Ocidental como Estado, o que impede seus representantes de apresentarem denúncias diretas ao Tribunal (Sántha et. al., 2010, pp. 181-183).

\section{A exploração econômica do Saara Ocidental ocupado pelo Marrocos}

A economia do Saara Ocidental se baseia na extraçáo de fosfato e na pesca em sua plataforma continental. Fosfatos são sais de fósforo utilizados como fertilizantes na agricultura. Deste mineral, 85\% se originam em sedimentos marinhos; encontram-se nos Estados Unidos, no Marrocos, no Saara Ocidental e no Oriente Médio (Souza e Fonseca, s/d).

A associação entre Marrocos e Espanha firmada no Acordo de Madri permitiu ao Marrocos tornar-se o maior exportador mundial de fosfato, explorando pesadamente as reservas do Saara Ocidental (Haugen, 2007, p. 75). Da mesma forma, o peixe da costa do Saara representa $40 \%$ de toda a produção pesqueira do Marrocos, que ainda permite a atuação de mais de cem grandes barcos de pesca espanhóis na região (Haugen, 2007, p. 74).

O Marrocos explora o fosfato saaraui na mina de Bou-Cra, embarcando o minério no porto de El-Aaiun, por meio de uma subsidiária de sua companhia estatal, a Officine Chérrifiene des Phosphates (OCP). De acordo com o relatório "P for Plunder", da Western Sahara Resources Watch (WSRW), a mina de Bou-Cra exportou 1 milhão de toneladas de fosfato em 2019, com uma receita estimada de 200 milhóes de dólares (considerado o preço internacional da commodity). Esse lucro foi revertido para o Marrocos, dono da controladora OCP (Western Sahara Resources Watch, 2020, p. 4).

Considerando que a autodeterminação implica a possibilidade de utilizar os próprios recursos naturais, a exploração econômica do Saara Ocidental sem consentimento expresso de seu representante - a Frente Polisario - infringe o artigo $73 \mathrm{da}$ Carta da ONU, bem como o artigo 55 da Convenção de Haia, de 1907, sobre direitos dos povos sob ocupação militar (Haugen, 2007, p. 76). Em vista disso, representantes saarauis têm feito campanha para conscientizar países e empresas a não adquirir fosfato proveniente do Saara Ocidental. Tal campanha resultou em uma diminuição de $80 \%$ nos embarques de fosfato no porto de El Aaiun desde 2010 (Western Sahara Resources Watch, 2020, p. 5).

Segundo o relatório, Estados Unidos e Canadá receberam seus últimos embarques de fosfato em 2018, e o número de empresas compradoras caiu de quinze, em 2011, para sete, em 2019. Hoje, os embarques são realizados para apenas quatro países: China, Índia e Nova Zelândia, que mantiveram 
suas importaçóes, e um novo cliente, que chega na contramão da tendência internacional, o Brasil (Western Sahara Resources Watch, 2020, p. 6).

Para Loureiro, Melamed e Figueiredo Neto (2009, p. 6), o aumento na produção de grãos da agricultura brasileira deve-se a uma maior e melhor aplicação de fertilizantes. A relativa pobreza dos solos brasileiros torna o fosfato um gargalo para o agronegócio do país. Tal necessidade pode ter levado à busca de novos mercados exportadores. Segundo a WSRW, aportaram no Brasil em 2019 dois cargueiros com fosfato extraído em território saaraui e carregado em portos ocupados, num total de 70.400 toneladas, estimado em US\$ 6 milhóes (Western Sahara Resources Watch, 2020, p. 14).

Dessa maneira, o Brasil passaria a figurar no rol dos países que, mesmo com uma posição diplomática historicamente firmada sobre o tema da autodeterminação, acaba por legitimar o espólio dos recursos naturais de um território não-autônomo e sem um poder administrativo em vigor. Para demonstrar o panorama no qual o Brasil construiu sua posição diplomática sobre o conflito, demonstraremos a forma como o país se vincula ao direito à autodeterminação dos povos e como este direito é aplicado pelo Itamaraty, especialmente no tocante ao Saara Ocidental.

\section{A autodeterminaçáo dos povos na Constituição Federal Brasileira}

O que os internacionalistas chamam de governança global, sociedade internacional ou ordem universal constitui - tanto no aspecto diplomático como estratégico -, ao mesmo tempo, um conjunto de regras e de cálculos de interesse e um código de valores (Cervo, 2008, p. 8). O código de valores que norteia a inserção internacional dos Estados é, geralmente, um constructo histórico. No caso brasileiro, no entanto, desde a ordem constitucional de 1988, esses valores são dispostos como princípios do país perante as relaçóes internacionais, no artigo $4^{\circ}$ da Constituição Federal de 1988.

A única inscrição na história constitucional nacional voltada a regular a atuação internacional do Estado brasileiro, o artigo representa um novo paradigma para a compreensão constitucional da matéria (Pannunzio, 2014, pp. 89-93). Ele define dez princípios e uma diretriz. A imensa maioria dos princípios constantes são constructos históricos provenientes do direito internacional, representando sua confluência e influência no direito constitucional brasileiro no tema (Lafer, 2005, p. 14; Pannunzio, 2014, p. 94).

O artigo estabelece como princípios da atuação do Brasil em suas relaçóes internacionais: a independência nacional; a prevalência dos direitos humanos; a autodeterminação dos povos (inciso III); a nãointervenção; a igualdade entre os Estados; a defesa da paz; a solução pacífica dos conflitos; o repúdio ao terrorismo e ao racismo; a cooperação entre os povos; e a concessão de asilo político. A diretriz estabelecida no parágrafo único trata da busca pela integração econômica, política, social e cultural dos povos da América Latina, visando a formação de uma comunidade latino-americana de naçóes (Brasil, 1988).

Assim, a Constituição de 1988 definiu, entre os princípios norteadores da inserção internacional, o resguardo ao direito à autodeterminação dos povos. A adoção deste princípio demonstra sua relevância e uma tradição em relação aos paradigmas históricos da política externa brasileira (Dallari, 1994, p. 163). Ecoa o entendimento de que os povos devem guiar-se por seus próprios meios, sem intervenção ou tutela estrangeira (Silva, 2005, p. 34).

A inserção do princípio no texto constitucional derivou da manifestação concreta dos governos brasileiros na execução de nossa política exterior, mesmo no tocante à reconstrução da ordem mundial no PósSegunda Guerra, com a instituição da Organização das Naçóes Unidas, que o ostenta como um de seus pilares, inscritos inclusive no bojo da Carta da ONU. ${ }^{2}$

\section{A política externa brasileira e a autodeterminação dos povos}

Ao longo do tempo, a diplomacia brasileira adquiriu extrema respeitabilidade no cenário internacional pela capacidade de conjugar valores nacionais ao que a sociedade internacional produz, tanto no aspecto multilateral quanto bilateral. Sobre a presença do direito à autodeterminação na prática diplomática nacional, podemos verificar que desde 
a gênese do ideário, com a Resolução 1514 (XV) da Assembleia Geral de 1960, o governo de Juscelino Kubitschek (1956-1961), na chancelaria de Horácio Lafer, manifesta-se favoravelmente à adoção daquela que viria a ser conhecida como a "Declaração de independência dos países e povos coloniais". A declaração inaugurou o período de legitimação do processo de descolonização ocorrido. A partir disso, a autodeterminação se tornou tema dominante daquela Assembleia Geral, e tradicional para a nossa diplomacia, constituindo-se como pilar retórico do Itamaraty (Cervo; Bueno, 2010, p. 306).

O governo Jânio Quadros, cuja chancelaria ficou a cargo de Afonso Arinos de Melo Franco, evidenciou que "Os princípios da autodeterminação e da nãointervenção seriam o norte das relações do Brasil no contexto hemisférico e mundial" (Cervo e Bueno, 2010, p. 315). Na 17a Assembleia Geral das Nações Unidas (1962), o chanceler afirmou que:

(...) O papel das Naçóes Unidas no processo histórico de liquidação do colonialismo decorre da letra e do espírito da Carta [das Naçóes Unidas]. O Princípio de Autodeterminação dos Povos é um dos alicerces de todo o edifício. O princípio de que as potências administradoras devem conduzir, como um "compromisso sagrado", os povos dependentes no caminho do governo próprio, estabelecido no capítulo XI da Carta, foi vigorosamente implementado pelas Resoluções 1514, 1541 e 1654 da Assembleia. Não existe expediente ou artifício que o possa obscurecer. O Brasil, por sua formação étnica e histórica, por sua tradição política e cultural é uma nação profundamente impregnada do sentimento anticolonialista. (Melo Franco, 1962)

No governo João Goulart (1961-1964), cuja chancelaria ficou a cargo, entre outros, de San Tiago Dantas, o Brasil manteve a posição de defesa da autodeterminação em relação, por exemplo, ao processo de independência da República de Angola, mesmo colocando em risco a relação com Portugal (Cervo e Bueno, 2010, p. 342).

Na Assembleia Geral de 1963, o chanceler João Augusto de Araújo Castro manifestou-se sobre a posição diplomática brasileira a respeito do princípio da autodeterminação dos povos afirmando que "a luta pela descolonização abrange todos os aspectos $\mathrm{da}$ luta secular pela liberdade e pelos direitos humanos. O Brasil é contra toda forma de colonialismo, seja político ou econômico" (Araújo Castro, 1963).

Mesmo durante o regime militar mantiveram-se princípios históricos da diplomacia brasileira, como "a autodeterminação dos povos, a não-intervenção em assuntos internos, a solução pacifica das controvérsias, a rejeição da conquista pelo uso da força, o respeito aos tratados [...]", entre outros (Cervo e Bueno, 2010, pp. 398-399). Em 1972, na visita do chanceler Brasileiro Mário Gibson Barbosa ao Senegal, a declaração emitida entre os Estados mencionava que os ministros de ambos

"demonstram a vontade de seus governos pela aplicação da Resolução 1514 (XV), de [...] 1960, sobre a outorga da independência aos países e povos coloniais", aduzindo que "para assegurar o progresso dos povos, é indispensável efetivar o direito soberano que possuem os Estados de proteger seus recursos naturais e deles dispor livremente, no contexto da autodeterminação." (Ministério das Relações Exteriores, 1972, p. 337-338).

Durante o governo Geisel (1974-1979), o chanceler Azeredo da Silveira buscou estreitar laços com os países africanos, estabelecendo embaixadas em vinte dos 37 países do continente (Cervo e Bueno, 2010, p. 421). No Senegal, em 1974, reafirmou os valores norteadores da política exterior brasileira para a África, a partir de três parâmetros: cooperação na modalidade Sul-Sul, em proveito do desenvolvimento mútuo; respeito aos princípios da soberania, autodeterminação e independência econômica das sociedades; e repulsa ao colonialismo e à discriminação racial (Cervo e Bueno, 2010, p. 422).

Após a redemocratização, o Brasil demonstrou grande empenho em posicionar-se frente a questóes como a da independência da Namíbia, do TimorLeste e, com maior expressão, no caso palestino; o presidente Luís Inácio Lula da Silva (2003-2010) reconheceu a existência internacional daquele estado nas fronteiras de 1967 (Ministério das Relaçôes Exteriores, 2010, p. 354). Assim, está demonstrada 
a vinculação histórica do Estado brasileiro no que tange à autodeterminação dos povos, perpassando o período da experiência democrática anterior ao regime militar e mesmo após a redemocratização.

\section{A política externa brasileira e o Saara Ocidental}

Entre os atos internacionais publicados pelo Itamaraty, são raras as mençóes ao caso do Saara Ocidental. Embora escassas, elas demonstram o posicionamento da diplomacia brasileira no tema. Por meio de comunicados publicados por ocasiáo do recebimento ou da realizaçáo de visitas oficiais, o governo brasileiro evidencia seu apoio, em primeiro lugar, à autodeterminação do Saara Ocidental e, em seguida, à resoluçấo do conflito via entendimentos sob a égide da ONU.

No comunicado emitido quando da visita do chanceler Ramiro Guerreiro a Moçambique, em 1980, ambas as naçóes declararam, sobre o Saara Ocidental, que "defendem a aplicação dos princípios da autodeterminação dos povos e da independência nacional proclamados pela Resoluçáo 1514 das Naçóes Unidas" (Ministério das Relaçôes Exteriores, 1980).

Em comunicado durante visita oficial à Nigéria em 1983, o general João Figueiredo afirmou que a crise no Saara Ocidental era motivo de crescente preocupação, e expressou a convicção de que a solução deveria ser buscada por meios pacíficos. A seguir, o presidente nigeriano relatou os esforços da Organização para a Unidade Africana (OUA) pela resolução pacífica do conflito. Figueiredo respondeu afirmando que seu país "apoiaria qualquer solução pacífica que surgisse destes esforços” (Ministério das Relações Exteriores, 1983). Ainda sob a chancelaria de Ramiro Guerreiro, em 1984, durante a visita da ministra dos Negócios Estrangeiros de São Tomé e Príncipe, o comunicado oficial entre as naçóes registra que ambas as autoridades manifestaram convicção de que "a solução da questão deve se basear no princípio de autodeterminação dos povos, conforme as resoluçóes pertinentes das Naçôes Unidas" (Ministério das Relaçóes Exteriores, 1984).

Em 1985, o chanceler Olavo Setúbal, em pronunciamento sobre o conflito na Câmara dos
Deputados, afirmou que a questão integra "um processo de descolonização não concluido"e que, "embora o Brasil reconheça a Frente Polisario como representante do povo saaraui", sempre manifestou posição "favorável ao princípio de autodeterminação e independência a ser implementado de forma pacifica e negociada" (Barreto, 2012, p. 38).

No relatório diplomático anual do Itamaraty de 1987 consta a visita do chanceler da República Árabe Saaraui Democrática, Ali Beida Mahfoud; recebido pelo "Ministro de Estado interino", ele reiterou "o desejo de seu governo de que o Brasil reconheça a RASD" (Ministério das Relações Exteriores, 1987, p. 36). O relatório do ano seguinte menciona o pedido, afirmando que as posiçóes brasileiras - não reconhecer a RASD, mas sim a Frente Polisario como "representante do povo saaraui", e o apoio à autodeterminação deste - "foram bem apreciadas pelos países do Magreb" (Ministério das Relaçóes Exteriores, 1988, p. 50).

Além disso, embora não componha o rol de países permanentes no Conselho de Segurança da ONU, o Brasil tem um histórico de votaçóes favoráveis ao entendimento entre as partes envolvidas no conflito. No único registro bibliográfico oficial relativo ao biênio 1998-1999 encontrado, o embaixador Gelson Fonseca Júnior resume a posiçáo brasileira sobre o tema afirmando que, embora "nenhum pronunciamento em sessão formal tenha sido feito pela delegação brasileira sobre a situação no Saara Ocidental em 1998-1999", esta participou de consultas informais, apoiando os esforços e as recomendaçóes do Secretário-Geral e a realização de um referendo livre, justo e transparente sobre a questão. O embaixador lamenta que "nenhum avanço adicional tenha sido observado" e reconhece que os "repetidos atrasos" no processo de definição dos critérios de habilitação para voto no referendo de autodeterminação "afetam a credibilidade do processo" (Barreto, 2012, p. 451).

No compêndio Resenhas da politica exterior do Brasil publicado pelo próprio Itamaraty, existem mençóes interessantes ao tema, como a nota intitulada "Comunicado dos ministros das Relaçóes Exteriores do Brasil, Celso Amorim, e do Marrocos, Mohamed Benaïssa, ocorrido em 12 de março de 2004", no qual ambos "reiteraram o apoio às decisóes do Conselho de Segurança das Naçôes Unidas, para alcançar uma 
solução política definitiva, negociada entre as partes" no que se menciona em relação ao conflito (Ministério das Relaçóes Exteriores, 2004a, p. 306).

No mesmo ano, por ocasião da visita ao Brasil do rei do Marrocos Mohamed VI, em novembro de 2004, o comunicado com o presidente Luís Inácio Lula da Silva inclui menção ao Saara Ocidental. A publicação registra que "o Presidente Lula reiterou o apoio brasileiro às decisóes do Conselho de Segurança da ONU para alcançar uma solução política negociada, por meio do diálogo entre as partes envolvidas na controvérsia" (Ministério das Relações Exteriores, 2004b, p. 460).

No ano de 2006, em nova reunião bilateral em Brasília, no "Comunicado da visita do Ministro dos Negócios Estrangeiros e da Cooperação do Marrocos, Mohamed Benaïssa”, o reino marroquino, em ofensiva, direciona pontualmente a declaração para a "questão do Saara" - e não do "Saara Ocidental” - e expóe sua intenção de edificar o "Magreb Árabe Unido", intuito original do ISTIQLAL. Posteriormente, o Brasil emite opiniāo oficial alinhada à legalidade internacional, reafirmando o "apoio aos esforços do Secretário-Geral das Naçóes Unidas e seu enviado pessoal para superar o impasse [...] e "avançar rumo a uma solução política mutuamente aceitável para a questão" (Ministério das Relaçóes Exteriores, 2006, p. 232-233).

Em nova visita ao Brasil, em 2007, os mesmos ministros emitiram outro comunicado. Neste, consta que o reino apresentou ao governo brasileiro a "proposta marroquina para a solução pacífica da questão do Saara Ocidental”. O plano tinha como intento a submissão do Saara Ocidental como região autônoma do Marrocos. Posteriormente submetido ao Conselho de Segurança da ONU, foi rechaçado de forma contundente pela Frente Polisario e pela República Árabe Saaraui Democrática (Jensen, 2012). A nota conjunta dá a entender que a visita teve como fim exclusivo a apresentação da "proposta". O chanceler Celso Amorim demonstrou novamente o apreço brasileiro à solução baseada no princípio da autodeterminação e nos mecanismos da ONU implicados na contenda, conforme se vê:

O Ministro Celso Amorim recebeu hoje, 14 de março, o Ministro das Relaçóes Exteriores do
Marrocos, Mohamed Benaïssa, que realiza visita a países sul-americanos, na qualidade de enviado do Rei Mohammed VI, para apresentar as linhas gerais da proposta marroquina para solução definitiva para a questáo do Saara Ocidental. O Ministro Celso Amorim reiterou a posição brasileira em favor de solução pacífica e duradoura para a questão, baseada no princípio da autodeterminação e nas resoluçóes pertinentes das Naçóes Unidas. Transmitiu ao Ministro Benaïssa sua esperança de que o diálogo e a cooperação entre as partes permitam superar diferenças e alcançar acordo político mutuamente satisfatório. (Ministério das Relaçôes Exteriores, 2007, p. 263)

Após a divulgação da nota, ocorreu inclusive o cancelamento de uma viagem oficial que o presidente Lula faria ao Marrocos em 2007. Oficialmente, o cancelamento abrupto teria partido de Mohammed VI, alegando "questóes pessoais e urgentes". A imprensa questionou aquilo que, "segundo fontes da área diplomática, foi um comunicado genérico e pouco esclarecedor" (Oliveira, 2007), e afirmou que o cancelamento se devera à não efetivação de um apoio claro à proposta marroquina de resoluçáo unilateral do conflito no Saara Ocidental. O chanceler Celso Amorim contradisse isso em entrevista, afirmando tratar-se de "um assunto importante e delicado. Reconhecemos sua importância para o Marrocos e outros países amigos, em especial a Argélia. É um assunto complexo" (Diário do Grande ABC, 2008, apud Estrada e Ricci, 2013). É importante acrescentar que, desde o início do governo do presidente Lula, o Marrocos mostrou-se simpático ao anseio brasileiro de tornar-se membro permanente do Conselho de Segurança das Naçóes Unidas; em que pesem as referidas declaraçóes, continuou apoiando os esforços brasileiros neste sentido (Ministério das Relações Exteriores, 2016). Nos governos da presidente Dilma Rousseff (2011-2016) e de Michel Temer (2016-2018) não ocorreram fatos relevantes sobre a temática.

No governo do atual presidente, Jair Messias Bolsonaro, entretanto, ocorre um aparente giro copernicano no pragmatismo diplomático brasileiro, no que se refere ao contencioso histórico envolvendo o princípio da autodeterminação, em especial no caso do Saara Ocidental. Em junho de 2019, o ministro 
das Relaçôes Exteriores Ernesto Araújo recebeu, em visita bilateral, o homólogo marroquino Nasser Bourita. Em declaração conjunta, os dois afirmam, sobre a questáo do Saara Ocidental, que esta seria "vital para o Marrocos", e que:

[...] o Brasil dá as boas-vindas e vê com muitos bons olhos a disposição do Marrocos de trabalhar rumo a soluçốes realistas para a questão do Saara, que é uma questão que já tem décadas e o Brasil tem todo interesse em contribuir, assim como qualquer outro diferendo que exista ao redor do mundo para soluçôes que vão além simplesmente da retórica e criem realmente novas bases de cooperação em todos os lugares do mundo na medida em que nós possamos contribuir. (Ministério das Relações Exteriores, 2019)

Assim, em sua manifestação, o ministro brasileiro dá alvíssaras à intenção do Marrocos de buscar "soluçôes realistas" para o conflito.

Existem evidências de que as relaçōes bilaterais brasileiro-marroquinas se baseiam exclusivamente na compra de fosfato. As taxas médias de comércio no fluxo de importação se situam na casa de US $\$ 1,4$ bilhóes, sendo o Brasil o terceiro maior parceiro comercial marroquino. Há potencial de prospecção para impulsionar a relação bilateral no fornecimento de produtos em matéria de defesa, já que, segundo o atual embaixador brasileiro em Rabat, o Marrocos "é um pais que tem vizinhos complexos, relaçôes complicadas com alguns deles, e devemos fornecer produtos [de defesa]" (Senado Notícias, 2019).

É evidente, ao longo do já exposto sobre o presente caso, que a conduta marroquina de invasão consiste, por si, em ato ilícito internacional, reprovado veementemente pela comunidade diplomática, e que a espoliação dos recursos naturais sem o consentimento do povo saaraui consiste na perpetuação dessa ilicitude. Diante da paralisia das negociaçôes conduzidas pela ONU, as "soluçóes realistas" a que o condutor atual da diplomacia brasileira se refere por certo se baseiam no plano unilateral de autonomia e submissão proposto ao Saara Ocidental, rejeitado pela Frente Polisario e não chancelado pelo Conselho de Segurança das Nações Unidas.
Diante do que vimos, é possível afirmar, sobre a postura do ministro Araújo, que há nela uma ponderação positiva das soluçóes para o conflito que vão "além da retórica" - uma alusão ao princípio da autodeterminação. Isso sugere uma guinada prómarroquina do Brasil, no que diz respeito ao conflito e aos interesses estratégicos nacionais, contrariando todo o histórico diplomático e os cânones constitucionais que vêm guiando o país em suas relações internacionais.

\section{A diplomacia do fosfato}

A espoliação do fosfato saaraui pelo Marrocos já tem repercussōes nas relaçôes econômicas a nível mundial. Em 2016, o Tribunal de Justiça da União Europeia excluiu os produtos originários do Saara Ocidental do Tratado de Livre-Comércio UE-Marrocos, proibindo sua comercialização, e declarou que o território saaraui é dissociado de qualquer outro do planeta, inclusive do Marrocos (Tribunal de Justiça da Uniáo Europeia, 2016).

No ano de 2017, o cargueiro marshallino NM Cherry Blossom carregou seus porôes com $54 \mathrm{mil}$ toneladas de fosfato saaraui e zarpou com destino à Nova Zelândia. Ao fazer escala em Port Elizabeth, na África do Sul - país que reconhece a RASD -, porém, foi apreendido, graças a uma ação judicial proposta pela Frente Polisario com base na ilegalidade da extração. O tribunal supremo da província de Cabo Oriental afirmou que "o fosfato em litígio pertence ao povo saaraui" e que nenhuma empresa marroquina teria o direito de adjudicá-lo ou mesmo vendê-lo (La Vanguardia, 2018). Este foi o primeiro caso judicial com desfecho contundente relativo à exploração de recursos naturais espoliados do Saara Ocidental. Ele atesta a vinculação real entre a situação jurídica do processo de descolonizaçáo, o direito de autodeterminação saaraui e a espoliação de recursos naturais por terceiros. $\mathrm{O}$ cargueiro ficou apreendido no porto por 370 dias.

Ainda em 2017, o navio singapuriano Ultra Innovation zarpou rumo ao Canadá carregado com fosfato saaraui, mas foi retido no Panamá por causa de alegaçóes de ilegalidade do produto. O tribunal marítimo panamenho o liberou uma semana depois, mediante pagamento de multa. Desde entáo, nenhum 
outro cargueiro proveniente do Saara Ocidental cruzou o Canal do Panamá (Western Sahara Resources Watch, 2020, p. 16).

Para o Brasil, a diplomacia marroquina do fosfato sempre foi uma alternativa viável, uma vez que o país possui demanda estratégica pela importação de fertilizantes. Contudo, a demanda estratégica pelo fosfato marroquino tem sido substituída pela recepção de navios provenientes do Saara Ocidental ocupado desde 2019. De acordo com os dados da Western Sahara Resources Watch (2020, p. 24), dois cargueiros - o Orient Tribune, de bandeira cipriota, e o Wulin, de bandeira hong-konguesa - aportaram no Brasil em julho e outubro de 2019, respectivamente em Salvador (Bahia) e Antonina (Paraná) e em Santos (São Paulo). Ambos estavam carregados de fosfato proveniente do território ocupado do Saara Ocidental, totalizando uma carga estimada em US\$ 6 milhóes.

Os fluxos comerciais de importação de fosfato, que estavam na casa de US\$ 1,4 bilhões em 2019, alcançaram a taxa de US\$2,2 bilhôes em 2010 (Senado Notícias, 2019). Soma-se a isso a instalação no Brasil, em 2010, da estatal marroquina OCP, que possui acordos mercantis com a gigante Yara Fertilizantes, e parte nos ativos financeiros da BUNGE Fertilizantes, além de acesso a diversos terminais portuários brasileiros. A empresa possui filiais em Paranaguá (PR), Rio Grande e Itaqui (RS), Rondonópolis (MT) e Aratu (BA), além de dois escritórios em São Paulo. Também prevê a inauguração, em 2020, de armazéns em Goiás, Minas Gerais, Pará e Santa Catarina (Daniel, 2019; O Globo, 2011; Ribeiro, 2013).

O projeto da Convenção sobre a Responsabilidade do Estado sobre Atos Ilícitos Internacionais da ONU dispóe que os Estados são juridicamente responsáveis pelos atos ilícitos de outros Estados quando prestam auxílio para o cometimento destes, mesmo que seja por meio de seus órgãos administrativos, e que essa responsabilidade decorra de atos compostos (Organização das Naçôes Unidas, 2002b). ${ }^{3}$ Assim, o Brasil passa a integrar o rol de Estados que importam e aceitam o desembaraço de recursos naturais espoliados do Saara Ocidental, em contradição com o histórico guia constitucional para suas relaçóes internacionais, com o posicionamento voltado ao direito de autodeterminaçáo dos povos e com a própria posição que assumiu em relação à questão do Saara Ocidental.

\section{Consideraçóes finais}

Conforme demonstrado no artigo, a invasão e a posterior ocupação militar do Saara Ocidental por Marrocos configuram ato ilícito internacional. O Acordo de Madri, que pretensamente o legitimou, não é considerado um instrumento jurídico válido para autorizar o domínio do país árabe sobre tal território. A guerra que se seguiu até 1991 e o imenso número de refugiados que surgiu dela fez com que a ONU interviesse diretamente por meio de uma missão de paz, cujo mandato ainda perdura. À ilegalidade da ocupação marroquina somam-se o cometimento de crimes de guerra e de crimes contra a humanidade, concretizados no território e contra o povo do Saara Ocidental.

Do ponto de vista econômico, destaca-se a espoliação de recursos naturais do povo saraaui pelo Marrocos, em especial o fosfato. A exploraçáo do mineral, controlada por empresa estatal marroquina, corrobora a hipótese do cometimento de ato ilícito internacional, já que tal prática, quando realizada em um território em vias de descolonização, deve ser feita com a concordância dos representantes do seu povo e em benefício do território. É o que dispóem o artigo 73 da Carta da ONU e os artigos 54 e 55 do Protocolos I, adicionados às Convençôes de Genebra de 1949, em 10 de junho de 1977, pela Conferência Diplomática sobre a Reafirmação e o Desenvolvimento do Direito Internacional Humanitário aplicável aos Conflitos Armados e internalizados pelo Decreto n. 849, de 25 de junho de 1993 (Brasil, 1993). No caso em questão, os recursos são auferidos por empresa do país invasor e o povo dominado permanece expulso do próprio território por um muro que o divide.

Diversas cortes domésticas e internacionais já se manifestaram a respeito da inalienabilidade do direito de autodeterminação do povo saaraui sobre seu território: a Corte Internacional de Justiça, em 1975; o Tribunal de Justiça da União Europeia, em 2016; a Corte Constitucional Sul-africana, em 2017; e até a Alta Corte do Reino Unido. em 2019. Ainda na Europa, Estados e mesmo empresas manifestam- 
se de forma evidente para restringir sua efetivação, por considerar ilegais os embarques provenientes dos portos do Saara Ocidental invadido e entender que tais práticas são ilegais.

Histórica e constitucionalmente, a República Federativa do Brasil apoiou a autodeterminaçáo do Saara Ocidental, da mesma maneira que defendeu diversos processos ao redor do globo desde a instituição da Resolução 1514 da 15a Assembleia Geral da ONU, em 1960. A diplomacia brasileira, pragmática e historicamente comprometida com o processo de governança global, e pela qual tantos grandes nomes da história nacional passaram, esquece o legado de apego à legalidade internacional e constitucional ao chancelar, a partir do governo Bolsonaro, a posiçáo marroquina em total confronto com o direito à autodeterminação do Saara Ocidental. Corrobora este fato o recebimento de fosfato saaraui por dois cargueiros provenientes do Saara Ocidental ocupado em 2019.

Em artigo recente amplamente veiculado na imprensa, o ex-presidente e ex-chanceler Fernando Henrique Cardoso, além dos ex-chanceleres Aloysio Nunes Ferreira, Celso Amorim, Celso Lafer, Francisco Rezek e José Serra, entre outros, afirmam a "preocupação com a sistemática violação, pela atual politica externa, dos princípios orientadores das relaçōes internacionais do Brasil definidos no artigo $4^{o}$ da Constituição de 1988". O texto afirma que a política externa de hoje traz resultados indesejáveis para o Brasil (Cardoso et. al., 2020).

Os fatos demonstram a participação consciente do Estado brasileiro na modalidade omissiva em relação à espoliação dos recursos naturais do território invadido do Saara Ocidental. Considerando que o país passou a receber embarques de fosfato do Saara Ocidental justamente quando grandes potências - como os EUA - reduziam a compra do produto, é possível supor, inclusive, a responsabilização internacional do Estado brasileiro, de acordo com o projeto da Convenção sobre a Responsabilidade do Estado sobre Atos Ilícitos Internacionais.

O posicionamento do Itamaraty sobre a questáo demonstra viés ideológico, ao abordar políticas que outrora compunham a raison d'etat, erigida solidamente ao longo da história, como meros quocientes da conjuntura governamental e não do processo de inserção internacional do Brasil, ignorando os pressupostos fundamentais do direito e das relaçóes internacionais. Neste sentido, urge que o Brasil retome sua tradição de respeito à autodeterminação, à prevalência dos direitos humanos e à solução pacífica dos conflitos na esfera internacional, proibindo a entrada no território brasileiro do fosfato falsamente chamado de "marroquino", extraído ilegalmente do Saara Ocidental.

\section{Notas}

1 Tradução dos autores.

2 Artigos $1^{\circ}$, parágrafo $2^{\circ}$; 55; 73; e 76 da Carta da ONU.

3 Conforme artigos $1^{\circ} ; 4^{\circ} ; 8^{\circ}$ e 16 .

\section{REFERÊNCIAS BIBLIOGRÁFICAS}

ACCIOLY, Hildebrando; SILVA, Geraldo Eulálio do Nascimento \& CASELLA, Paulo Borba. (2009), Manual de direito internacional público. $17^{\mathrm{a}}$ edição, São Paulo, Saraiva.

ANISTIA INTERNACIONAL. (2019), Morocco and Western Sahara. Disponível em https://www. amnesty.org/en/countries/middle-east-and-northafrica/morocco-and-western-sahara/moroccoand-western-sahara/, acessado em 12/01/2021.

ARAÚJO CASTRO, João Augusto. (1963), “Discurso do Representante do Brasil (Sr. Araújo Castro) na XVIII Assembleia Geral das Naçôes Unidas, em 19 de setembro de 1963", in TRINDADE, Antônio Augusto Cançado, Repertório da Prática Brasileira do Direito Internacional Público (Periodo 1961-1981), 2a edição, Brasília, FUNAG, 2012.

ARSO. (s/d), "O acordo de Madrid". Disponível em http://www.arso.org/hist7-p.htm, acessado em 11/01/2021.

BARRETO, Fernando de Mello. (2012), A política externa após a redemocratizaçáo. Tomo I - 19852002. Brasília, FUNAG.

BRASIL, República Federativa do. (1988), Constituição da República Federativa de 1988. Disponível em http://www.planalto.gov.br/ccivil_03/constituicao/ constituicao.htm, acessado em 11/01/2021. 
BRASIL, República Federativa do. (1993), "Decreto no 849, de 25 de junho de 1993”. Disponível em http://www.planalto.gov.br/ccivil_03/ decreto/1990-1994/D0849.htm, acessado em $11 / 01 / 2021$.

CARDOSO, Fernando Henrique; FERREIRA, Aloysio Nunes; AMORIM, Celso; REZEK, Francisco; SERRA, José; RICUPERO, Rubens \& KALOUT, Hussein. (2020), "A reconstrução da política externa brasileira". Folha de S. Paulo, 8 mai. Disponível em https://www1.folha.uol. com.br/mundo/2020/05/a-reconstrucao-dapolitica-externa-brasileira.shtm, acessado em $11 / 01 / 2021$.

CERVO, Amado Luiz. (2008), Inserção internacional: formação dos conceitos brasileiros. São Paulo, Saraiva.

CERVO, Amado Luiz \& BUENO, Clodoaldo. (2010), História da política exterior do Brasil. Brasília, UNB.

CORTE INTERNACIONAL DE JUSTIÇA. (1975), Western Sahara. Advisory Opinion. Disponível em https://www.icj-cij.org/public/files/caserelated/61/061-19751016-ADV-01-00-EN.pdf, acessado em 18/01/2021.

DALLARI, Pedro Bohomoletz de Abreu. (1994), Constituição e relações exteriores. São Paulo, Saraiva.

DANIEL, Isaura. "Marroquina OCP reforça estrutura no Brasil”. (2019), Agência de Notícias BrasilÁrabe, 14 nov. Disponível em https://anba.com. $\mathrm{br} /$ marroquina-ocp-reforca-estrutura-no-brasil/, acessado em 12/01/2021.

ESTRADA, Rodrigo Duque \& RICCI, Carla. (2013), "A política externa brasileira e a questão do Saara Ocidental: a dinâmica da neutralidade e as possibilidades de engajamento". Revista Perspectiva. 6, 10:43-61. Disponível em https://seer.ufrgs.br/ RevistaPerspectiva/issue/viewIssue/2608/157, acessado em 11/01/2021.

FRIEDRICH, Tatyana Scheila. (2004), As normas imperativas de direito internacional público jus cogens. Belo Horizonte, Fórum.

HAUGEN, Hans Morten. (2007), “The Right to Self-Determination and Natural Resources: The case of Western Sahara”. Lead - Law, Environment and Development Journal, 3, 1:70-82. Disponível em http://www.lead-journal.org/content/07070. pdf, acessado em 11/01/2021.

HUMAN RIGHTS WATCH. (2019), "Morocco/ Western Sahara - Events of 2018”. Disponível em https://www.hrw.org/world-report/2019/ country-chapters/morocco/western-sahara, acessado em 11/01/2021.

HUMAN RIGHTS WATCH. (2017), "Morocco/ Western Sahara: Torture Allegations Cast Shadow Over Trial”, 17 jul. Disponível em https://www. hrw.org/news/2017/07/17/morocco/westernsahara-torture-allegations-cast-shadow-over-trial, acessado em 11/01/2021.

JENSEN, Erik. (2012), Western Sahara: Anatamy of a Stalemate? 2a edição. Londres, Lynne Rienner.

"Joint venture de Yara e OCP importará rocha fosfática no Brasil”. (2011), O Globo, 14 dez. Disponível em http://g1.globo.com/economia/ agronegocios/noticia/2011/12/joint-venture-deyara-e-ocp-importara-rocha-fosfatica-no-brasil. html, acessado em 11/01/2021.

KALPAKIAN, Jack. (2006), "Managing Morocco's Image in United States Domestic Politics". The Journal of North African Studies, 11, 1:56-69.

KORMIKIARI, Maria Cristina Nicolau. (2001). "Grupos indígenas berberes na Antiguidade: a documentação textual e epigráfica”. Revista de História, 145, 1:9-60.

LAFER, Celso. (2005), A internacionalização dos direitos humanos: Constituição, racismo e relaçôes internacionais. Barueri, Manole.

LOUREIRO, Francisco Eduardo Lapido; MELAMED, Ricardo Gonçalves \& FIGUEIREDO NETO, Jackson. (2009), Fertilizantes, agroindústria e sustentabilidade. Rio de Janeiro, CETEM/MCT.

McKENNA, Amy. (2010), The History of Northern Africa. Nova York, Britannica Educational.

MELO FRANCO, Afonso Arinos de. (1962), "Discurso do Representante do Brasil (Sr. Melo Franco), na XVI Assembleia Geral da ONU, em 20 de setembro de 1962", in TRINDADE, Antônio Augusto Cançado. Repertório da prática brasileira do direito internacional público (periodo 1961-1981). 2a edição, Brasília, FUNAG, 2012. 
MIGUEL, Carlos Ruiz. (1995), El Sahara Occidental y España: Historia, Política y Derecho. Analisis Crítico de La Política Exterior Española. Madri, Dykinson.

MINISTÉRIO DAS RELAÇŌES EXTERIORES. (2019), "Ministro Ernesto Araújo recebe chanceler do Marrocos". Disponível em https://www. youtube.com/watch?v=M9_fSBGj28E, acessado em 11/01/2021.

MINISTÉRIO DAS RELAÇÓES EXTERIORES. (2016), "Comunicado conjunto Brasil-Marrocos - Rabat 2016”. Disponível em https://www.gov.br/mre/ptbr/canais_atendimento/imprensa/notas-a-imprensa/ comunicado-conjunto-adotado-por-ocasiao-davisita-oficial-do-ministro-das-relacoes-exterioresda-republica-federativa-do-brasil-a-convite-doministro-dos-negocios-estrangeiros-e-da-cooperacaodo-reino-do-marrocos-rabat-10-de-marco-de-2016, acessado em 11/01/2021.

MINISTÉRIO DAS RELAÇŌES EXTERIORES. (2010), "Reconhecimento do Estado Palestino nas fronteiras de 1967. Resenha de Política Exterior do Brasil, 37, 107:354. Disponível em http:// www.itamaraty.gov.br/images/ed_biblioteca/ resenhas_peb/resenha107_2_2010.pdf, acessado em 11/01/2021.

MINISTÉRIO DAS RELAÇÓES EXTERIORES. (2007), "Visita ao Brasil do ministro das Relaçōes Exteriores do Marrocos, Mohammed Benaïssa". Resenha de Política Exterior do Brasil, 34, 100:263. Disponível em http://www.itamaraty. gov.br/images/ed_biblioteca/resenhas_peb/ Resenha_N100_1Sem_2007.pdf, acessado em 11/01/2021.

MINISTÉRIO DAS RELAÇŌES EXTERIORES. (2006), "Comunicado conjunto da visita oficial ao Brasil do ministro dos Negócios Estrangeiros e da Cooperação do Marrocos, Mohamed Benaïssa". Resenha de Politica Exterior do Brasil, 33, 98:230. Disponível em http://www.itamaraty. gov.br/images/ed_biblioteca/resenhas_peb/ Resenha_N98_1Sem_2006.pdf, acessado em 11/01/2021.

MINISTÉRIO DAS RELAÇÓES EXTERIORES. (2004a), "Comunicado conjunto dos ministros das Relaçóes Exteriores do Brasil e do Marrocos".
Resenha de Política Exterior do Brasil, 31, 94:305. Disponível em http://www.itamaraty.gov.br/ images/ed_biblioteca/resenhas_peb/Resenha_ N94_1Sem_2004.pdf, acessado em 11/01/2021. MINISTÉRIO DAS RELAÇÓES EXTERIORES. (2004b), "Visita ao Brasil do rei do Marrocos, Mohammed VI - Comunicado conjunto". Resenha de Política Exterior do Brasil, 31, 95:458. Disponível em http://www.itamaraty.gov.br/ images/ed_biblioteca/resenhas_peb/Resenha_ N95_2Sem_2004.pdf, acessado em 11/01/2021.

MINISTÉRIO DAS RELAÇÓES EXTERIORES. (1988), Relatório 1988. Disponível em http:// www.funag.gov.br/chdd/images/Relatorios/ Relat\%C3\%B3rio\%201988.pdf, acessado em $11 / 01 / 2021$.

MINISTÉRIO DAS RELAÇÓES EXTERIORES. (1987), Relatório 1987. Disponível em http:// www.funag.gov.br/chdd/images/Relatorios/ Relat\%C3\%B3rio\%201987.pdf, acessado em $11 / 01 / 2021$.

MINISTÉRIO DAS RELAÇÓESS EXTERIORES. (1984), "Comunicado conjunto entre o governo da República Federativa do Brasil e o governo da República Democrática de São Tomé e Príncipe". Disponível em https://concordia.itamaraty.gov. br/detalhamento-acordo/3198, acessado em 11/01/2021.

MINISTÉRIO DAS RELAÇÓES EXTERIORES. (1983), "Comunicado conjunto entre o governo da República Federativa do Brasil e o governo da República Federal da Nigéria”. Disponível em https://concordia.itamaraty.gov.br/detalhamentoacordo/3120, acessado em 11/01/2021.

MINISTÉRIO DAS RELAÇÓES EXTERIORES. (1980), "Comunicado conjunto entre República Federativa do Brasil e República Popular de Moçambique". Disponível em https://concordia. itamaraty.gov.br/detalhamento-acordo/2730, acessado em 11/01/2021.

MINISTÉRIO DAS RELAÇÓES EXTERIORES. (1972), "Declaração conjunta Brasil/Senegal, 21 de novembro de 1972 (Visita do ministro Mário Gibson Barboza ao Senegal)" in TRINDADE, Antônio Augusto Cançado. Repertório da prática 
brasileira do direito internacional público (período 1961-1981). 2a edição, Brasília, FUNAG, 2012. MIYARES, Águeda Mera. (2013), El Sáhara Occidental: ¿Un conflicto olvidado? Disponível em https://www.idhc.org/arxius/recerca/SaharaOccidental_ cast.pdf, acessado em 12/01/2021.

MUNDY, Jacob. (2006), "Neutrality or Complicity? The United States and the 1975 Moroccan Takeover of Spanish Sahara”. The Journal of North African Studies, 11, 3:275-306.

NUZZO, Luigi. (2012), “Colonial Law”. EGO - European History Online. Disponível em http:// www.ieg-ego.eu/en/threads/europe-and-the-world/ european-overseas-rule/luigi-nuzzo-colonial-law, acessado em 11/01/2021.

OLIVEIRA, Eliane. "Lula cancela viagem ao Marrocos". (2007), O Globo, 30 mai. Disponível em https:// oglobo.globo.com/economia/lula-cancela-viagemmarrocos-4185625, acessado em 12/01/2021.

ORGANIZAÇÃO DAS NAÇÓES UNIDAS. (2020), "United Nations Missions for the Referendum in Wester Sahara (MINURSO)”. Disponível em https://minurso.unmissions.org/, acessado em 12/01/2021.

ORGANIZAÇÃO DAS NAÇŌES UNIDAS. (2002a), "Letter dated 29 January 2002 from the UnderSecretary-General for Legal Affairs, the Legal Counsel, addressed to the President of the Security Council". Disponível em http://www.havc.se/res/ SelectedMaterial/20020129legalopinionwesternsahara. pdf, acessado em 12/01/2021.

ORGANIZAÇÃO DAS NAÇÓES UNIDAS. (2002b), "Resolution Adopted by the General Assembly”. Disponível em https://www.un.org/ en/ga/search/view_doc.asp?symbol=A/RES/56/83, acessado em 12/01/2021.

ORGANIZAÇÃO DAS NAÇÓES UNIDAS. (1991), "The Situation Concerning Western Sahara”. Disponível em https://www.un.org/ga/ search/view_doc.asp?symbol=S/RES/690(1991), acessado em 12/01/2021.

ORGANIZAÇÁO DAS NAÇÓES UNIDAS. (1990), "Resolution 658”. Disponível em https:// undocs.org/es/S/RES/658\%20(1990), acessado em 12/01/2021.
ORGANIZAÇÃO DAS NAÇÓES UNIDAS. (1975), "Resolution 380 (1975)". Disponível em https:// undocs.org/es/S/RES/380\%20(1975), acessado em 12/01/2021.

ORGANIZAÇÃO DAS NAÇÓES UNIDAS. (1974), "Resolução da Assembleia Geral 3292 (XXIX) de 1974”. Disponível em https://undocs.org/es/A/ RES/3292(XXIX), acessado em 17/01/2021.

ORGANIZAÇÃO DAS NAÇÓES UNIDAS. (1966), "Resolução da Assembleia Geral 2229 (XXI) de 1966”. Disponível em https://undocs.org/es/A/ RES/2229(XXI), acessado em 18/01/2021.

ORGANIZAÇÃO DAS NAÇÕES UNIDAS. (1960), "Declaração sobre a concessão da independência aos países e povos coloniais". Disponível em http://www.dhnet.org.br/direitos/sip/onu/spovos/ dec60.htm, acessado em 12/01/2021.

PANNUNZIO, Eduardo. (2014), Judicialização das relaçôes internacionais: a força do princípio constitucional da prevalência dos direitos humanos. São Paulo, Saraiva.

PAONE, Mariangela. "Human Rights Watch confirma la cifra de muertos reconocida por Marruecos". (2010), El País, 19 nov. Disponível em https:// elpais.com/internacional/2010/11/19/actualidad/1290121216_850215.html, acessado em $11 / 01 / 2021$.

PENNA FILHO, Pio. (2010), "A difícil e esquecida questão do Saara Ocidental”. Boletim Meridiano, 11, 114:3-5. Disponível em: http://seer.bce. unb.br/index.php/MED/article/view/474/294, acessado em 12/01/2021.

"Relaçóes entre Brasil e Marrocos atingiram 'um patamar mais alto', garante diplomata”. (2019), Senado Notícias, 27 jun. Disponível em https://www12. senado.leg.br/noticias/materias/2019/06/27/relacoes-entre-brasil-e-marrocos-atingiram-2018um-patamar-mais-alto2019-garante-diplomata, acessado em 12/01/2021.

RIBEIRO, Clarissa Correia Neto. (2017). "Marrocos e União Africana: entre integração e desintegração regional”. Observatório de Regionalismo, 27 mar. Disponível em http://observatorio.repri. org/2017/03/27/marrocos-e-uniao-africana-entre-integracao-e-desintegracao-regional/, acessado em 12/01/2021. 
RIBEIRO, Luci. "CADE aprova compra de fatia da Bunge pela OCP”. (2013), Exame, 27 nov. Disponível em https://exame.com/negocios/ cade-aprova-compra-de-fatia-da-bunge-pelaocp-2/, acessado em 11/01/2021.

SANTAYANA, Mauro. (1987), Dossiê da Guerra do Saara. Rio de Janeiro, Paz e Terra.

SÁNTHA, Hanga; HARTMANN, Ylva Lennartsson \& KLAMBERG, Mark. (2010), "Crimes Against Humanity in Western Sahara: The Case Against Morocco". Juridisk Publikation. 2, 3:175-199. Disponível em http://juridiskpublikation.se/ wp-content/uploads/2014/10/22010_HangaS\%C3\%A1 ntha-Ylva-Lennartsson-Hartmann-ochMark-Klamberg.pdf, acessado em 12/01/2021.

SILVA, Alexandre Pereira da. (2005), "Os princípios da autodeterminação dos povos e da não-intervenção: análise de um caso prático", in BRANDÃO, José Maurício \& ADEODATO, Claudio. Direito ao extremo: coletânea de estudos, Rio de Janeiro, Forense.

SOUZA, Antônio Eleutério de \& FONSECA, David Siqueira. (s/d), "Fosfato". Série Estatísticas e Economia Mineral. Disponível em https:// www.gov.br/anm/pt-br/centrais-de-conteudo/ publicacoes/serie-estatisticas-e-economia-mineral/ outras-publicacoes-1/7-2-fosfatohttp://www.dnpm. gov.br/dnpm/publicacoes/serie-estatisticas-e-economia-mineral/outras-publicacoes-1/7-2-fosfato, acessado em 12/01/2021.

"Sudáfrica falla a favor del Sáhara en pleito por cargamento de fosfato". (2018), La Vanguardia, 23 fev. Disponível em https://www.lavanguardia. com/politica/20180223/441008377915/sudaf- rica-falla-a-favor-del-sahara-en-pleito-por-cargamento-de-fosfato.html, acessado em 11/01/2021. SUZIN, Giovana Moraes \& DAUDÉN, Laura. (2011), Nem paz nem guerra. Três décadas de guerra no Saara Ocidental. Rio de Janeiro, Tinta Negra/Bazar Editorial.

THOMAS, Martin. (2002), "Defending a Lost Cause? France and the United States Vision of Imperial Rule in French North Africa, 1945-1956". Diplomatic History, 26, 2:215-247.

TRIBUNAL DE JUSTIÇA DA UNIÃO EUROPEIA. (2016), "Sentencia del Tribunal de Justicia". Disponível em http://curia.europa.eu/juris/ document/document.jsf?docid $=186489 \&$ mode $=$ req \& pageIndex $=1 \&$ dir $=\&$ occ $=-$ first $\&$ part $=1 \&$ text $=\&$ doclang $=E S \&$ cid $=1021060$, acessado em 12/01/2021.

WESTERN SAHARA RESOURCES WATCH. (2020), "P for Plunder: Morocco's exports of phosphates from occupied Western Sahara”. Disponível em https://www.wsrw.org/files/dated/2020-0224/p_for_plunder_2020-web.pdf, acessado em 12/01/2021.

WRANGE, Pal. (2019), "Self-Determination, Occupation and The Authority to Exploit Natural Resources: Trajectories from four European Judgements on Western Sahara”. Israel Law Review, 52, 1:3-29. Disponível em https://www.cambridge.org/core/ journals/israel-law-review/article/selfdetermination-occupation-and-the-authority-to-exploit-natural-resources-trajectories-from-four-european-judgments-on-western-sahara/25DB600AF2F5E86B30EFFB88F57CF69F, acessado em 12/01/2021.

ZUNES, Stephen. (1998) “The United States and the Western Sahara Peace Process". Middle East Policy, 5, 4:131-146. 


\section{O PRAGMATISMO E A RUPTURA NA POLÍTICA EXTERNA BRASILEIRA PARA O SAARA OCIDENTAL}

\section{Adriano Alberto Smolarek, João Irineu de Resende Miranda}

Palavras-chave: Saara Ocidental; Marrocos; Brasil; Ato Ilícito Internacional; Fosfato.

Este artigo analisa a posição brasileira sobre o conflito entre o Marrocos e o Saara Ocidental. No centro da discussão desse conflito está o direito do Saara Ocidental a sua autodeterminação. $\mathrm{O}$ princípio da autodeterminação dos povos está previsto na Constituição brasileira e é parte indissociável das manifestaçóes diplomáticas ao longo da história. No entanto, a atual chancelaria tem emitido declaraçôes que evidenciam uma ruptura da tradição brasileira nesse tema. Este artigo analisa a seguinte questão: o que teria motivado o atual governo a descumprir o princípio da autodeterminação e abandonar uma tradição histórica da diplomacia brasileira? Tendo o método dedutivo e a documentaçáo indireta como técnicas de pesquisa, abordou-se a situação do Saara Ocidental e um ato internacional ilícito cometido pelo Marrocos. Sobre o Brasil, realizou-se pesquisa histórica e documental do posicionamento sobre a autodeterminação dos povos. Ao final, constatou-se que fatores comerciais motivaram a mudança do posicionamento brasileiro sobre o conflito em questão.

\section{PRAGMATISM AND BREACH IN BRAZILIAN FOREIGN POLICY FOR WESTERN SAHARA}

\section{Adriano Alberto Smolarek, João Irineu de Resende Miranda}

Keywords: Western Sahara; Morocco; Brazil; International State Wrongful Act; Phosphate.

This article analyzes the Brazilian position on the conflict between Morocco and Western Sahara. Central to the discussion of this conflict is Western Sahara's right to self-determination. The principle of selfdetermination is provided in the Brazilian Constitution and is an inseparable part of diplomatic demonstrations throughout history. However, the current chancellery has issued statements that show a rupture in the Brazilian tradition on this topic. This article intends to analyze the following question: what would have motivated the current government to breach the principle of self-determination and abandon the Brazilian diplomacy's historical tradition? Through the deductive method and indirect documentation as a research technique, the situation of Western Sahara and the international illegal committed by Morocco were addressed. Historical and documentary research on the positioning of self-determination was carried out from Brazilian perspective. In the end, it was found that commercial factors motivated the change in the Brazilian position on the present conflict.

\section{PRAGMATISME ET INFRACTION DANS LA POLITIQUE ÉTRANGÈRE BRÉSILIENNE POUR LE SAHARA OUEST}

\author{
Adriano Alberto Smolarek, Joáo Irineu \\ de Resende Miranda
}

Mots-clés: Sahara occidental; Maroc; Brésil;
Acte Illicite International; Phosphate.

Cet article analyse la position brésilienne sur le conflit entre le Maroc et le Sahara occidental. Le droit du Sahara occidental à l'autodétermination est au cour de la discussion de ce conflit. Le principe de l'autodétermination des peuples est inscrit dans la Constitution brésilienne et fait partie intégrante des manifestations diplomatiques à travers l'histoire. Cependant, la chancellerie actuelle a publié des déclarations qui montrent une rupture dans la tradition brésilienne sur ce sujet. Cet article se propose d'analyser la question suivante: Qu'est-ce qui aurait motivé le gouvernement actuel à violer le principe de l'autodétermination et à abandonner la tradition historique de la diplomatie brésilienne? Par la méthode déductive et la documentation indirecte comme technique de recherche, la situation du Sahara Occidental et l'acte illégal international commis par le Maroc ont été abordés. Sur le Brésil, des recherches historiques et documentaires sur le positionnement de l'autodétermination des peuples ont été menées. Finalement, il a été constaté que des facteurs commerciaux avaient motivé le changement de position du Brésil sur le conflit actuel. 